\title{
Association of Low Blood Pressure with White Matter Hyperintensities in Elderly Individuals with Controlled Hypertension
}

\author{
Jun Sung Kim, ${ }^{\text {a }}$ Subin Lee, ${ }^{\mathrm{a}}$ Seung Wan Suh, ${ }^{\mathrm{b}}$ Jong Bin Bae, ${ }^{\mathrm{b}}$ Ji Hyun Han, ${ }^{\mathrm{b}}$ Seonjeong Byun, ${ }^{\mathrm{b}}$ \\ Ji Won Han, Jae Hyoung Kim, ${ }^{\mathrm{c}}$ Ki Woong Kim ${ }^{\mathrm{a}, \mathrm{b}, \mathrm{d}}$ \\ ${ }^{a}$ Department of Brain and Cognitive Science, Seoul National University College of Natural Sciences, Seoul, Korea \\ ${ }^{b}$ Department of Neuropsychiatry, Seoul National University Bundang Hospital, Seoul National University College of Medicine, Seongnam, Korea \\ 'Department of Radiology, Seoul National University Bundang Hospital, Seoul National University College of Medicine, Seongnam, Korea \\ ${ }^{d}$ Department of Psychiatry, Seoul National University College of Medicine, Seoul, Korea
}

Background and Purpose Both hypertension and hypotension increase cerebral white matter hyperintensities. However, the effects of hypotension in individuals with treated hypertension are unknown. We analyzed the association of low blood pressure with the location and amount of white matter hyperintensities between elderly individuals with controlled hypertension and those without hypertension.

Methods We enrolled 505 community-dwelling, cognitively normal elderly individuals from the participants of the Korean Longitudinal Study on Cognitive Aging and Dementia. We measured blood pressure three times in a sitting position using a mercury sphygmomanometer and defined low systolic and diastolic blood pressure as $\leq 110$ and $\leq 60 \mathrm{~mm} \mathrm{Hg}$, respectively. We segmented and quantified the periventricular and deep white matter hyperintensities from 3.0 Tesla fluidattenuated inversion recovery magnetic resonance images.

Results Low systolic blood pressure was independently associated with larger volume of periventricular white matter hyperintensity $(P=0.049)$. The interaction between low systolic blood pressure and hypertension was observed on the volume of periventricular white matter hyperintensity $(P=0.005)$. Low systolic blood pressure was associated with the volume of periventricular white matter hyperintensity in individuals with controlled hypertension $\left(F_{1,248}=6.750\right.$, $P=0.010)$, but not in those without hypertension $(P=0.380)$. Low diastolic blood pressure was not associated with the volumes of white matter hyperintensities regardless of presence of controlled hypertension.

Conclusions Low systolic blood pressure seems to be associated with larger volume of periventricular white matter hyperintensity in the individuals with a history of hypertension but not in those without hypertension.
Correspondence: Ki Woong Kim Department of Neuropsychiatry, Seoul National University Bundang Hospital, Seoul National University College of Medicine, 82 Gumi-ro 173beon-gil, Bundang-gu, Seongnam 13620, Korea Tel: +82-31-787-7432

Fax: +82-31-787-4058

E-mail:kwkimmd@snu.ac.kr

Received: July 17, 2019

Revised: September 27, 2019

Accepted: October 21, 2019

Keywords Hypertension; Hypotension; Blood pressure; White matter hyperintensity; Old 


\section{Introduction}

Although cerebral white matter hyperintensities (WMHs) are not rare in healthy elderly individuals, they are commonly associated with cognitive disorders, mood disorders, and impaired physical function. ${ }^{1,2}$ WMHs are usually sub-classified into periventricular WMH and deep WMH according to the "continuity to ventricle" rule. ${ }^{3}$ Periventricular and deep WMHs have been associated with different etiologies; periventricular WMH is due to hemodynamic insufficiency (hypoperfusion), ${ }^{2,4-7}$ whereas deep WMH is due to small vessel diseases. ${ }^{2,8-10}$

Hypertension can cause both cerebral hypoperfusion ${ }^{11-13}$ and small vessel disease $\mathrm{e}^{14,15}$ and has been associated with the presence and amount of both periventricular $\mathrm{WMH}^{16,17}$ and deep WMH. ${ }^{18,19}$ In hypertension, cerebral hypoperfusion is known to result from the increased vascular resistance and disturbed hemodynamic flow patterns, ${ }^{11-13,20,21}$ whereas the small vessel disease results from endothelial dysfunction of the blood-brain barrier. ${ }^{22}$ Recently, Divisón-Garrote et al..$^{23}$ using the Spanish Society of Hypertension Ambulatory Blood Pressure Monitoring (ABPM) Registry, showed that hypotension is relatively common in patients with treated hypertension, particularly among elderly individuals. One in three elderly patients with treated hypertension attended in routine clinical practice was potentially at risk of having hypotension, and more than half of them had masked hypotension. ${ }^{23}$ Hypotension is also known to increase the risk of WMHs by inducing cerebral hypoperfusion. ${ }^{24}$ In the Cardiovascular Determinants of Dementia Study, both increases and decreases in the diastolic blood pressure (BP) were associated with an increased incidence of periventricular WMH in elderly patients without dementia.

Compared to the individuals without hypertension, those with hypertension may be more vulnerable to cerebral hypoperfusion because their upper and lower boundaries of cerebral autoregulation may be upshifted. ${ }^{25-28}$ However, the effect of hypotension on cerebral WMHs in patients with treated hypertension has never been directly investigated. In this study, we compared the association of hypotension on cerebral WMHs between elderly individuals with controlled hypertension and those without hypertension.

\section{Methods}

\section{Participants}

This study was conducted as a part of the Korean Longitudinal Study on Cognitive Aging and Dementia (KLOSCAD). The KLOSCAD is an ongoing, nationwide, population-based, prospective cohort study on cognitive aging and dementia in the elderly. ${ }^{29}$
In the KLOSCAD, 6,818 community-dwelling Koreans, aged 60 years or older, who were randomly sampled from 30 villages or towns across South Korea, completed the baseline assessment, which was conducted from November 2010 through October 2012. Among them, 505 cognitively normal participants without hypertension or with controlled hypertension who were enrolled from Yongin, Gyeonggi-do were included in the current study (Table 1). We excluded the participants with any of the following conditions: cognitive disorders, including dementia and mild cognitive impairment (MCl); major neurologic and psychiatric disorders; substance use disorders; and cardiovascular diseases, including uncontrolled hypertension with an office-measured systolic BP over $140 \mathrm{~mm} \mathrm{Hg}$ or diastolic BP over $90 \mathrm{~mm} \mathrm{Hg}$.

All participants or their legal guardians provided written informed consent for study participation. The study was approved by the Institutional Review Board of the Seoul National University Bundang Hospital, Korea.

\section{Assessments}

A trained research nurse measured the BP three times (at the beginning, middle, and at the end of the clinical assessment when the participants visited the hospital) over the participants' right arm brachial artery, in a sitting position, using a mercury sphygmomanometer (No. 300-V, Tanaka Sangyo Co. Ltd., Tokyo, Japan). To reduce bias, the mean value of the three measurements was used for the analysis.

According to the presence of controlled hypertension, we subclassified the participants into two groups: those with controlled hypertension $(\mathrm{HT}+)$ and those without a history of hypertension (HT-). According to the current office-measured systolic BP, we also sub-classified the participants into two groups: low systolic BP group (LSBP), comprising those with a current systolic BP of $110 \mathrm{~mm} \mathrm{Hg}$ or below, and not-low systolic BP group (NSBP), comprising those with a current systolic BP above $110 \mathrm{~mm} \mathrm{Hg}$, but below $140 \mathrm{~mm} \mathrm{Hg}$. According to the current office-measured diastolic BP, we sub-classified the participants into the following two groups: low diastolic BP group (LDBP), comprising those with a current diastolic BP of $60 \mathrm{~mm} \mathrm{Hg}$ or below, and not-low diastolic BP group (NDBP), comprising those with a current diastolic BP between 61 and $90 \mathrm{~mm} \mathrm{Hg}$.

Geriatric psychiatrists with expertise in dementia research performed face-to-face, standardized diagnostic interviews; physical and neurological examinations; laboratory tests, including complete blood counts, chemistry profiles, and serological tests for syphilis; echocardiography; and chest X-ray imaging, using the Korean version of the Consortium to Establish a Registry for Alzheimer's Disease Assessment Packet (CERAD-K) Clinical Assessment Battery ${ }^{30}$ and the Korean version of the Mini Inter- 


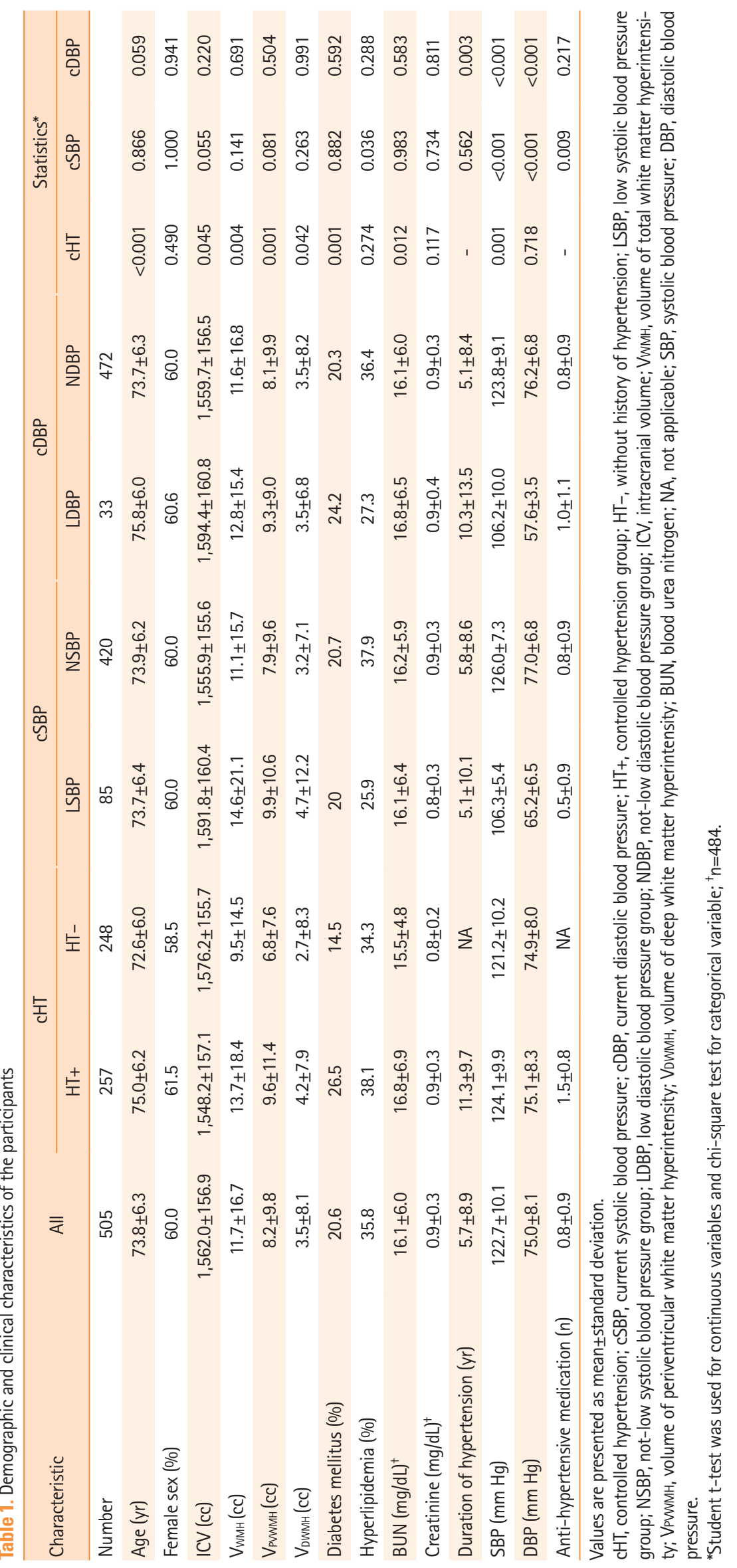


national Neuropsychiatric Interview. ${ }^{31}$ A research neuropsychologist or a trained research nurse administered the CERAD-K Neuropsychological Assessment Battery, ${ }_{1}^{30,32}$ Digit Span Test, ${ }_{1}^{33}$ and Frontal Assessment Battery ${ }^{34}$ to each participant. All participants performed -1.0 SD of the age-, sex-, and education-adjusted norms for elderly Koreans on the Mini-Mental State Examination. ${ }^{35} \mathrm{~A}$ panel of four research geriatric psychiatrists confirmed the final diagnosis for each participant. We diagnosed dementia and other axis I mental disorders according to the diagnostic criteria of the Diagnostic and Statistical Manual of Mental Disorders, Fourth Edition, for dementia ${ }^{36}$ and $\mathrm{MCl}$, according to the consensus criteria proposed by the International Working Group on $\mathrm{MCl} .{ }^{37}$ Participants were considered cognitively normal if they did not exhibit any evidence of cognitive impairment that altered their daily activities and were functioning independently in the community.

\section{Magnetic resonance imaging acquisition and processing}

All participants underwent magnetic resonance imaging (MRI) on a 3.0 Tesla GE SIGNA Scanner (GE Healthcare, Milwaukee, WI, USA). The MRI protocol included the following sequences: $\mathrm{T}_{1}$ (acquired voxel size $=1.0 \mathrm{~mm}^{3} \times 0.5 \mathrm{~mm}^{3} \times 0.5 \mathrm{~mm}^{3}$, field of view $=240 \mathrm{~mm} \times 240 \mathrm{~mm}, 175 \times 240 \times 240$ matrix in the $x-$, $\mathrm{y}-$, and $\mathrm{z}$ - dimensions, $1.0 \mathrm{~mm}$ sagittal slices with no interslice gap, echo time $=3.68 \mathrm{~ms}$, repetition time $=25.0 \mathrm{~ms}$, number of excitations $=1$, and flip angle $=90^{\circ}$ ) and fluid-attenuated inversion recovery (FLAIR) (acquired voxel size $=0.5 \mathrm{~mm}^{3} \times 0.5$ $\mathrm{mm}^{3} \times 3.0 \mathrm{~mm}^{3}$, field of view $=240 \mathrm{~mm} \times 240 \mathrm{~mm}$, acquisition axial plane matrix size $=256 \mathrm{~mm} \times 256 \mathrm{~mm}, 3.0-\mathrm{mm}$ axial slices thickness with no interslice gap, echo time $=160 \mathrm{~ms}$, repetition time $=9,900 \mathrm{~ms}$, number of excitations $=1$, flip angle $=90^{\circ}$, and inversion time $=2,500 \mathrm{~ms}$ )

The major steps of WMH image processing were as follows: (1) we obtained $T_{1}$-weighted magnetic resonance (MR) images in all participants and we applied a bias field correction (BC) using the Statistical Parametric Mapping software version 8 (SPM8, Wellcome Trust Centre for Neuroimaging, London, UK) to correct the low-frequency and to smooth the signal that corrupts the MR images; (2) we re-sliced the BC- $\mathrm{T}_{1}$-weighted MR images into isotropic voxels $\left(1.0 \mathrm{~mm}^{3} \times 1.0 \mathrm{~mm}^{3} \times 1.0\right.$ $\mathrm{mm}^{3}$ ); (3) we used the in-house code of MATLAB 2014a (MATLAB and Statistics Toolbox Release 2014a, The MathWorks Inc., Natick, MA, USA) to spatially normalize the re-sliced BC- $T_{1}$ weighted MR images to the Korean normal elderly brain template (KNE96) $)^{38}$ and to allow for an inter-individual ventricle extraction; (4) we used the fully automated in-house code of MATLAB 2014a to spatially normalize the native spaced FLAIR images to the International Consortium for Brain Mapping template (ICBM) $)^{39}$ and to allow for an inter-individual WMH segmentation, ${ }^{40}$ and we calculated the total volume of the WMHs ( $\left(\mathrm{V}_{\text {ммн }}\right)$; (5) we performed co-registration between the re-sliced $B C-T_{1}$-weighted $M R$ images and the segmented $\mathrm{WMH}$ image of the same participants; and (6) we further sub-classified the WMHs into periventricular and deep WMHs, and the relative volumes ( $\mathrm{V}_{\mathrm{PW} M H}$ and $\mathrm{V}_{\mathrm{DWMH}}$, respectively) were calculated according to the distance rule, ${ }^{2,4}$ using the fully automated in-house code of MATLAB 2014a.

We estimated the intracranial volume (ICV) of each participant using the Freesurfer software version 5.3.0 (http://surfer. nmr.mgh.harvard.edu) and used it as a covariate to consider the individual intracranial size variation.

\section{Statistical analysis}

We compared the continuous and categorical variables between the groups using Student's t-test and Pearson's chisquare test, respectively. We examined the association of controlled hypertension, systolic and diastolic hypotension, and their interactions on the $\mathrm{V}_{\text {WMH, }} \mathrm{V}_{\text {PUWMH, }}$ and $\mathrm{V}_{\text {DWMH }}$ using analysis of variance (ANOVA) that computed the age, ICV, hyperlipidemia, diabetes mellitus (DM), number of antihypertensive medication and duration of hypertension as covariates. We analyzed the association of systolic hypotension on the $\mathrm{V}_{\mathrm{Puw}}$ in the HT+ and HT- groups separately, using ANOVA that computed the age, ICV, hyperlipidemia, DM, diastolic BP, number of antihypertensive medication and duration of hypertension as covariates.

For all analyses, we used the SPSS for Windows version 20.0 (IBM Co., Armonk, NY, USA), and considered a two-sided P-value less than 0.05 as statistically significant.

\section{Results}

The subjects in the HT+ group were slightly older, more likely to have DM, and showed modestly higher systolic BP than did those in the HT- group. The subjects in the HT+ group also had a larger $\mathrm{V}_{\text {WMH, }} \mathrm{V}_{\text {PVWMH, }}$ and $\mathrm{V}_{\text {DWMH }}$ than did those in the HTgroup. The subjects in the LSBP group were more likely to have hyperlipidemia than were those in the NSBP group. The blood urea nitrogen and creatinine were comparable between LSBP and NSBP group and between LDBP and NDBP group. LDBP group had longer duration of hypertension than those in NDBP group. In the LSBP and LDBP groups, $\mathrm{V}_{\mathrm{WMH}_{1}} \mathrm{~V}_{\mathrm{P} \mathrm{WWM}}$, and $\mathrm{V}_{\mathrm{DWMH}}$ were comparable to those in the NSBP and NDBP groups, respectively, in the unadjusted analyses. The number of antihypertensive medication was also comparable between LSBP and 
NSBP groups and between LDBP and NDBP group (Table 1).

In the analysis of covariance (ANCOVA) that adjusted for age, ICV, hyperlipidemia, DM, number of antihypertensive medication and duration of hypertension, systolic BP $\left(F_{1,492}=3.887, P=0.049\right)$ and its interaction with hypertension $\left(F_{1,492}=7.836, P=0.005\right)$ (Table 2) were associated with larger $V_{\text {PUwMH, }}$ but not with the $V_{\text {DWMH }}$ (Table 2). When we analyzed the association of LSBP with the $\mathrm{V}_{\mathrm{PWw}}$ in the HT+ and HT- groups separately, LSBP was associated with the $\mathrm{V}_{\text {PvwM }}$ in the HT+ group, but not in the HT- group (Table 3). In the HT+ group, the subjects in the LSBP group had approximately 1.7 times larger $V_{\text {PVwM }}$ than did those the NSBP group $\left(F_{1,248}=6.750\right.$, $P=0.010$ ) (Table 3). However, in the HT- group, the $V_{P w w m H}$ was comparable between the LSBP and NSBP groups $\left(F_{1,243}=0.774\right.$, $P=0.380$ ) (Table 3 ). In contrast to low systolic $B P$, low diastolic BP was not associated with the $\mathrm{V}_{\text {WMH, }}, \mathrm{V}_{\text {PWwMH, }}$ nor the $\mathrm{V}_{\mathrm{DWMH}}$ (Table 2).

\section{Discussion}

This study revealed that lower systolic BP and its interaction with hypertension, though controlled, was associated with a larger $\bigvee_{\text {Рuwm }}$ in the participants with controlled hypertension.
The association of hypertension and WMHs has been repeatedly reported in previous cross-sectional and prospective studies. In the Cardiovascular Determinants of Dementia (CASCADE) study, higher systolic BP was associated with more severe periventricular and deep WMHs. ${ }^{41}$ In the Epidemiology of Vascular Aging study, hypertension at baseline was associated with an increased risk of having severe WMHs at the 4-year follow-up evaluation. ${ }^{42}$ In the Rotterdam Scan Study, hypertension at baseline was associated with an increased risk of both periventricular and deep WMHs, particularly in the elderly. ${ }^{43}$

When hypertension was controlled, the risk of WMHs due to hypertension was also reduced. ${ }^{42,43}$ However, in the CASCADE study, the participants with poorly controlled hypertension were found to have a higher risk of WMHs than those with an untreated hypertension, ${ }^{41}$ which may be in line with our observation that the periventricular WMH were larger in the participants with controlled hypertension who had a low systolic BP. More than $8 \%$ of the patients with treated hypertension were found to have a low systolic BP. ${ }^{44}$ Previous studies showed that hypotension alone can result cerebral hypoperfusion; however, a more severe cerebral hypoperfusion was observed in the participants with hypertension, ${ }^{12}$ which, even if controlled, may cause by damaging the cerebral autoregulation. ${ }^{45,46}$ Cerebral

Table 2. Association between history of hypertension, current blood pressure group and its interaction on volume of cerebral white matter hyperintensities*

\begin{tabular}{|c|c|c|c|c|c|c|}
\hline \multirow{2}{*}{ Variable } & \multicolumn{2}{|c|}{$V_{\text {WMH }}$} & \multicolumn{2}{|c|}{$V_{\text {PWWMH }}$} & \multicolumn{2}{|c|}{$V_{\text {DWMH }}$} \\
\hline & $\mathrm{F}$ & $P$ & $\mathrm{~F}$ & $P$ & $\mathrm{~F}$ & $P$ \\
\hline Hypertension & 0.011 & 0.916 & 0.002 & 0.960 & 0.073 & 0.788 \\
\hline SBP group & 3.586 & 0.059 & 3.887 & 0.049 & 2.281 & 0.132 \\
\hline DBP group & 0.341 & 0.559 & 0.296 & 0.587 & 0.292 & 0.589 \\
\hline SBP groupxDBP group & 3.497 & 0.062 & 3.747 & 0.053 & 2.257 & 0.134 \\
\hline SBP groupxHypertension & 5.788 & 0.016 & 7.836 & 0.005 & 2.489 & 0.115 \\
\hline DBP groupxHypertension & 1.168 & 0.280 & 2.414 & 0.121 & 0.136 & 0.713 \\
\hline
\end{tabular}

VWMH, volume of total white matter hyperintensity; $\mathrm{V}_{\mathrm{PWw}}$, volume of periventricular white matter hyperintensity; $V_{\mathrm{VWMH}}$, volume of deep white matter hyperintensity; SBP, systolic blood pressure; DBP, diastolic blood pressure.

*Analysis of covariance adjusted for intracranial volume, age, hyperlipidemia, diabetes mellitus, number of antihypertensive medications and duration of hypertension as covariates; d.f=1,492.

Table 3. Association of systolic blood pressure on the volume of periventricular white matter hyperintensity in participants with controlled hypertension and those without hypertension

\begin{tabular}{lccccc}
\hline \multirow{2}{*}{ Variable } & \multicolumn{3}{c}{ VPwMH } & \multicolumn{3}{c}{ Statistics $^{*}$} \\
\cline { 2 - 6 } & LSBP & NSBP & F & d.f & $P$ \\
\hline HT+ group $(n=257)$ & $15.2 \pm 13.3$ & $8.8 \pm 11.0$ & 6.750 & 1,248 & 0.010 \\
HT-group $(n=248)$ & $7.0 \pm 7.5$ & $6.7 \pm 7.6$ & 0.774 & 1,243 & 0.380 \\
\hline
\end{tabular}

Values are presented as mean \pm standard deviation (cc).

$V_{\text {Puwm }}$, volume of periventricular white matter hyperintensity; LSBP, low systolic blood pressure group; NSBP, not-low systolic blood pressure group; HT+, participants with controlled hypertension; HT-, participants without hypertension.

${ }^{*}$ Analysis of covariance adjusted for intracranial volume, age, hyperlipidemia, diabetes mellitus, diastolic blood pressure, number of antihypertensive medications and duration of hypertension as covariates. 
autoregulation is the innate capacity of the cerebral vasculature to maintain a constant cerebral blood flow (CBF) ${ }_{1}^{47}$ which allows adequate blood supply to the brain to meet the ample metabolic demands. ${ }^{48}$ Cerebral autoregulation in normotensive individuals is relatively constant, maintaining a fixed range of mean arterial pressure (MAP) between 60 and $150 \mathrm{~mm} \mathrm{Hg} .{ }^{49}$ When the MAP is within this range, the blood flow is actively controlled by changes in the arteries. However, when the MAP is below or above this range, blood supply may not be properly maintained, inducing damage to the brain. ${ }^{48}$ Patients with hypertension were found to have upshifted upper and lower limits of cerebral autoregulation ${ }^{25,26}$ and a higher cerebrovascular resistance compared with the normotensive controls, despite their global resting CBF and cerebral oxygen consumption being comparable to those in the normotensive controls..$^{50}$

In this study, low diastolic BP was not associated with the volumes of the periventricular nor deep WMHs, which is in line with the findings of previous research on the association of BPs on cerebral perfusion. The Joint National Committee on Prevention, Detection, Evaluation, and Treatment of High Blood Pressure reported that systolic BP is a more important vascular risk factor than diastolic BP in subjects aged over 50 years. ${ }^{51}$ Glodzik et al. ${ }^{52}$ found that the cortical and hippocampal blood flows were negatively associated with the systolic BP, but not with the diastolic BP. In addition, they found that the cortical and hippocampal blood flows decreased as the systolic BP decreased during a 2-year follow-up period, whereas the same were not influenced by the decrease of diastolic BP in the same period. $.^{52} \mathrm{How}-$ ever, the effect of low diastolic BP warrants further investigation because the number of the participants with low diastolic BP was only 33 in the current study. Furthermore, low diastolic BP, which has been repeatedly reported to increase the WMHs in previous research, was not associated with the $V_{\text {WMH }}$ in both the $\mathrm{HT}-$ and $\mathrm{HT}+$ groups in the current study.

We defined LSBP as being below $110 \mathrm{~mm} \mathrm{Hg}$ in the current study because several studies reported that a low systolic BP below $90 \mathrm{~mm} \mathrm{Hg}$ lacked clinical sensitivity. Eastridge et al. ${ }^{53}$ have studied the relevance of systolic BP in the mortality rate among 81,134 participants. The baseline mortality of the participants was $<2.5 \%$. However, with the systolic BP at $110 \mathrm{~mm} \mathrm{Hg}$, the slope of mortality rate increased and was $4.8 \%$ greater for every decrement of $10 \mathrm{~mm} \mathrm{Hg}$ in the systolic BP. ${ }^{53}$ Edelman et al. ${ }^{54}$ reported that among patients with gastric, small bowel, and/or diaphragm injuries, the mortality was higher in those with an systolic BP below $110 \mathrm{~mm} \mathrm{Hg} \mathrm{(5 \% )} \mathrm{than} \mathrm{in} \mathrm{those} \mathrm{with} \mathrm{an} \mathrm{systolic}$ BP of $110 \mathrm{~mm} \mathrm{Hg}$ or higher (1\%). We also defined LDBP as being below $60 \mathrm{~mm} \mathrm{Hg}$. Guichard et al..$^{55}$ investigated BP and heart failure in 5,376 elderly participants and found that isolated dia- stolic hypotension, which was defined as a diastolic BP below 60 $\mathrm{mm} \mathrm{Hg}$, was a significant independent risk factor for heart failure. In the Oxford Project to Investigate Memory and Aging (OPTIMA) study, ${ }_{1}^{56}$ a low diastolic BP, defined as a diastolic BP below $60 \mathrm{~mm} \mathrm{Hg}$, was related to a faster cognitive decline among patients with Alzheimer's disease.

There are several limitations in the current study. First, this study had a cross-sectional design. Second, we did not conduct a 24-hour ambulatory BP monitoring in the current study despite that BP is highly dynamic. Third, our multivariable analyses may not have fully adjusted all potential factors that may confound the association of BP and WMHs. Further study needs to compensate variables that may affect the BP or WMHs. Fourth, whether the low systolic BP in the participants with controlled hypertension is attributable to overtreatment of the hypertension or to underlying structural or functional abnormalities that are associated with predisposition to $\mathrm{WMHs}$ cannot be definitively determined.

\section{Conclusions}

This study provides the evidence that systolic hypotension, after hypertensive condition, may increase $\mathrm{V}_{\text {ришмн. }}$. It is not common to individuals without history of hypertension or normotensive individuals. Elderly individuals with hypertension on treatment may be at the higher risk of periventricular WMH if they suffer hypotension

\section{Disclosure}

The authors have no financial conflicts of interest.

\section{Acknowledgments}

The authors thank all members of the staff and the participants of the Korean Longitudinal Study of Aging and Dementia (KLOSCAD) study for their important contributions.

This study was supported by a grant from the Korean Health Technology R\&D Project, Ministry of Health, Welfare, Republic of Korea (grant no. HI09C1379 [A092077]) and a grant from the Research of Korea Centers for Disease Control and Prevention (grant no. 2019-ER6201-00).

\section{References}

1. Breteler MM, van Swieten JC, Bots ML, Grobbee DE, Claus JJ, van den Hout JH, et al. Cerebral white matter lesions, vascular risk factors, and cognitive function in a population-based 
study: the Rotterdam Study. Neurology 1994;44:1246-1252.

2. Kim KW, MacFall JR, Payne ME. Classification of white matter lesions on magnetic resonance imaging in elderly persons. Biol Psychiatry 2008;64:273-280.

3. Fazekas F, Chawluk JB, Alavi A, Hurtig HI, Zimmerman RA. MR signal abnormalities at $1.5 \mathrm{~T}$ in Alzheimer's dementia and normal aging. AJR Am J Roentgenol 1987;149:351-356.

4. Griffanti $L$, Jenkinson $M$, Suri $S$, Zsoldos $E$, Mahmood $A$, Filippini $N$, et al. Classification and characterization of periventricular and deep white matter hyperintensities on MRI: a study in older adults. Neuroimage 2018;170:174-181.

5. Markus HS, Lythgoe DJ, Ostegaard L, O'Sullivan M, Williams SC. Reduced cerebral blood flow in white matter in ischaemic leukoaraiosis demonstrated using quantitative exogenous contrast based perfusion MRI. J Neurol Neurosurg Psychiatry 2000;69:48-53.

6. ten Dam VH, van den Heuvel DM, de Craen AJ, Bollen EL, Murray HM, Westendorp RG, et al. Decline in total cerebral blood flow is linked with increase in periventricular but not deep white matter hyperintensities. Radiology 2007;243: 198-203.

7. Fazekas $F$, Kleinert $R$, Offenbacher $H$, Schmidt R, Kleinert $G$, Payer $F$, et al. Pathologic correlates of incidental MRI white matter signal hyperintensities. Neurology 1993;43:1683-1689.

8. Rosenberg GA, Wallin A, Wardlaw JM, Markus HS, Montaner J, Wolfson L, et al. Consensus statement for diagnosis of subcortical small vessel disease. J Cereb Blood Flow Metab 2016;36:6-25.

9. Sachdev P, Parslow R, Salonikas C, Lux O, Wen W, Kumar R, et al. Homocysteine and the brain in midadult life: evidence for an increased risk of leukoaraiosis in men. Arch Neurol 2004;61:1369-1376.

10. Shi Y, Wardlaw JM. Update on cerebral small vessel disease: a dynamic whole-brain disease. Stroke Vasc Neurol 2016;1:8392.

11. Choi JY, Cui Y, Kim BG. Interaction between hypertension and cerebral hypoperfusion in the development of cognitive dysfunction and white matter pathology in rats. Neuroscience 2015;303:115-125.

12. de la Torre JC. Cardiovascular risk factors promote brain hypoperfusion leading to cognitive decline and dementia. Cardiovasc Psychiatry Neurol 2012;2012:367516.

13. Tzourio C. Hypertension, cognitive decline, and dementia: an epidemiological perspective. Dialogues Clin Neurosci 2007;9:61-70.

14. Jiménez-Balado J, Riba-Llena I, Abril O, Garde E, Penalba A, Ostos $E_{1}$ et al. Cognitive impact of cerebral small vessel disease changes in patients with hypertension. Hypertension
2019;73:342-349.

15. Liu Y, Dong YH, Lyu PY, Chen WH, Li R. Hypertension-induced cerebral small vessel disease leading to cognitive impairment. Chin Med J (Engl) 2018;131:615-619.

16. Lindgren A, Roijer A, Rudling 0, Norrving B, Larsson EM, Eskilsson $J$, et al. Cerebral lesions on magnetic resonance imaging, heart disease, and vascular risk factors in subjects without stroke. A population-based study. Stroke 1994; 25:929-934.

17. Fukuda H, Kitani M. Differences between treated and untreated hypertensive subjects in the extent of periventricular hyperintensities observed on brain MRI. Stroke 1995;26:15931597.

18. Gao Z, Wang W, Wang Z, Zhao X, Shang Y, Guo Y, et al. Cerebral microbleeds are associated with deep white matter hyperintensities, but only in hypertensive patients. PLoS One 2014;9:e91637.

19. Hannawi Y, Yanek LR, Kral BG, Vaidya D, Becker LC, Becker $D M$, et al. Hypertension is associated with white matter disruption in apparently healthy middle-aged individuals. AJNR Am J Neuroradiol 2018;39:2243-2248.

20. de la Torre JC. Cerebral hemodynamics and vascular risk factors: setting the stage for Alzheimer's disease. J Alzheimers Dis 2012;32:553-567.

21. O'Rourke MF, Hashimoto J. Mechanical factors in arterial aging: a clinical perspective. J Am Coll Cardiol 2007;50:1-13.

22. Cuadrado-Godia E, Dwivedi P, Sharma S, Ois Santiago A, Roquer Gonzalez J, Balcells $M$, et al. Cerebral small vessel disease: a review focusing on pathophysiology, biomarkers, and machine learning strategies. J Stroke 2018;20:302-320.

23. Divisón-Garrote JA, Ruilope LM, de la Sierra A, de la Cruz JJ,

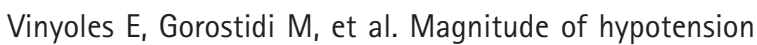
based on office and ambulatory blood pressure monitoring: results from a cohort of 5066 treated hypertensive patients aged 80 years and older. J Am Med Dir Assoc 2017;18:452.

24. Román GC. Brain hypoperfusion: a critical factor in vascular dementia. Neurol Res 2004;26:454-458.

25. Strandgaard S. Autoregulation of cerebral blood flow in hypertensive patients. The modifying influence of prolonged antihypertensive treatment on the tolerance to acute, druginduced hypotension. Circulation 1976;53:720-727.

26. Strandgaard S, Olesen J, Skinhoj E, Lassen NA. Autoregulation of brain circulation in severe arterial hypertension. Br Med J 1973;1:507-510.

27. de la Torre JC. Critically attained threshold of cerebral hypoperfusion: the CATCH hypothesis of Alzheimer's pathogenesis. Neurobiol Aging 2000;21:331-342.

28. van Beek $A H$, Claassen JA, Rikkert MG, Jansen RW. Cerebral 
autoregulation: an overview of current concepts and methodology with special focus on the elderly. J Cereb Blood Flow Metab 2008;28:1071-1085.

29. Han JW, Kim TH, Kwak KP, Kim K, Kim BJ, Kim SG, et al. Overview of the Korean longitudinal study on cognitive aging and dementia. Psychiatry Investig 2018;15:767-774.

30. Lee JH, Lee KU, Lee DY, Kim KW, Jhoo JH, Kim JH, et al. Development of the Korean version of the Consortium to Establish a Registry for Alzheimer's Disease Assessment Packet (CERAD$\mathrm{K})$ : clinical and neuropsychological assessment batteries. $J$ Gerontol B Psychol Sci Soc Sci 2002;57:P47-P53.

31. Yoo SW, Kim YS, Noh JS, Oh KS, Kim CH, NamKoong K, et al. Validity of Korean version of the mini-international neuropsychiatric interview. Anxiety Mood 2006;2:50-55.

32. Lee DY, Lee KU, Lee JH, Kim KW, Jhoo JH, Kim SY, et al. A normative study of the CERAD neuropsychological assessment battery in the Korean elderly. J Int Neuropsychol Soc 2004; 10:72-81.

33. Wechsler D. WMS-R: Wechsler Memory Scale-Revised Manual. Cleveland, $\mathrm{OH}$ : Psychological Corporation, 1984.

34. Kim TH, Huh Y, Choe JY, Jeong JW, Park JH, Lee SB, et al. Korean version of frontal assessment battery: psychometric properties and normative data. Dement Geriatr Cogn Disord 2010;29:363-370.

35. Kim JL, Park JH, Kim BJ, Kim MD, Kim SK, Chi YK, et al. Interactive influences of demographics on the Mini-Mental State Examination (MMSE) and the demographics-adjusted norms for MMSE in elderly Koreans. Int Psychogeriatr 2012; 24:642-650.

36. American Psychiatric Association. DSM-IV-TR: Diagnostic and Statistical Manual of Mental Disorders, Text Revision. Washington, DC: American Psychiatric Association, 2000.

37. Winblad B, Palmer K, Kivipelto $M$, Jelic V, Fratiglioni $L$, Wahlund LO, et al. Mild cognitive impairment: beyond controversies, towards a consensus: report of the International Working Group on Mild Cognitive Impairment. J Intern Med 2004;256:240-246.

38. Lee $\mathrm{H}$, Yoo BI, Han JW, Lee JJ, Oh SY, Lee EY, et al. Construction and validation of brain MRI templates from a Korean normal elderly population. Psychiatry Investig 2016;13:135-145.

39. Mazziotta JC, Toga AW, Evans A, Fox P, Lancaster J. A probabilistic atlas of the human brain: theory and rationale for its development. The International Consortium for Brain Mapping (ICBM). Neuroimage 1995;2:89-101.

40. Yoo BI, Lee JJ, Han JW, Oh SY, Lee EY, MacFall JR, et al. Application of variable threshold intensity to segmentation for white matter hyperintensities in fluid attenuated inversion recovery magnetic resonance images. Neuroradiology 2014;
56:265-281.

41. van Dijk EJ, Breteler MM, Schmidt R, Berger K, Nilsson LG, Oudkerk $M$, et al. The association between blood pressure, hypertension, and cerebral white matter lesions: cardiovascular determinants of dementia study. Hypertension 2004;44:625630.

42. Dufouil $C_{1}$ de Kersaint-Gilly A, Besançon V, Levy C, Auffray $E_{1}$ Brunnereau $L$, et al. Longitudinal study of blood pressure and white matter hyperintensities: the EVA MRI cohort. Neurology 2001;56:921-926.

43. de Leeuw FE, de Groot JC, Oudkerk M, Witteman JC, Hofman $A$, van Gijn J, et al. Hypertension and cerebral white matter lesions in a prospective cohort study. Brain 2002;125(Pt 4):765-772.

44. Divisón-Garrote JA, Banegas JR, De la Cruz JJ, Escobar-Cervantes $C_{1}$ De la Sierra A, Gorostidi $M$, et al. Hypotension based on office and ambulatory monitoring blood pressure. Prevalence and clinical profile among a cohort of 70,997 treated hypertensives. J Am Soc Hypertens 2016;10:714-723.

45. Ruland S, Aiyagari V. Cerebral autoregulation and blood pressure lowering. Hypertension 2007;49:977-978.

46. Shekhar S, Liu R, Travis OK, Roman RJ, Fan F. Cerebral autoregulation in hypertension and ischemic stroke: a mini review. J Pharm Sci Exp Pharmacol 2017;2017:21-27.

47. Immink RV, van den Born BJ, van Montfrans GA, Koopmans RP, Karemaker JM, van Lieshout JJ. Impaired cerebral autoregulation in patients with malignant hypertension. Circulation 2004;110:2241-2245.

48. Jordan JD, Powers WJ. Cerebral autoregulation and acute ischemic stroke. Am J Hypertens 2012;25:946-950.

49. Paulson $O B$, Strandgaard S, Edvinsson L. Cerebral autoregulation. Cerebrovasc Brain Metab Rev 1990;2:161-192.

50. Kety SS, Hafkenschiel JH, Jeffers WA, Leopold IH, Shenkin HA. The blood flow, vascular resistance, and oxygen consumption of the brain in essential hypertension. J Clin Invest 1948;27: 511-514

51. Chobanian AV, Bakris GL, Black HR, Cushman WC, Green LA, Izzo JL Jr, et al. The seventh report of the joint national committee on prevention, detection, evaluation, and treatment of high blood pressure: the JNC 7 report. JAMA 2003;289:25602572.

52. Glodzik L, Rusinek H, Tsui W, Pirraglia E, Kim HJ, Deshpande $A$, et al. Different relationship between systolic blood pressure and cerebral perfusion in subjects with and without hypertension. Hypertension 2019;73:197-205.

53. Eastridge BJ, Salinas J, McManus JG, Blackburn L, Bugler EM, Cooke WH, et al. Hypotension begins at $110 \mathrm{~mm} \mathrm{Hg}$ : redefining "hypotension" with data. J Trauma 2007;63:291-297. 
54. Edelman DA, White MT, Tyburski JG, Wilson RF. Post-traumatic hypotension: should systolic blood pressure of 90-109 mmHg be included? Shock 2007;27:134-138.

55. Guichard JL, Desai RV, Ahmed MI, Mujib M, Fonarow GC, Feller MA, et al. Isolated diastolic hypotension and incident heart failure in older adults. Hypertension 2011;58:895-901.

56. Razay G, Williams J, King E, Smith AD, Wilcock G. Blood pressure, dementia and Alzheimer's disease: the OPTIMA longitudinal study. Dement Geriatr Cogn Disord 2009;28:70-74. 